\title{
An Owner's Approach to Managing the Structural Performance of VLCCs
}

\author{
by D T Melitz*, Member, E J Robertson**, Member \\ N J Davison***, Member
}

\begin{abstract}
Summary
An owner's experience with structural design and performance of a wide range of ship types (oil tankers, gas tankers, semi submersibles and tanker based production systems) has enabled a new approach to be devised to assessing the structural durability of a class of 5 VLCCs. These vessels were built in the mid 1970s and are experiencing varying degrees of corrosion, dependent on their operational life.

The approach adopted combined conventional ship structural design techniques with structural dynamics, and fatigue and fracture mechanics techniques more commonly used in UK North Sea Offshore Projects. The combination of these technologies has led to the development of a structural management strategy for the operation of these VLCCs.

The strategy has three basic components : structural enhancement, structural inspection and structural monitoring at sea. The formulation of each component is described in detail. Installation of a stress monitoring system on five ships (4 VLCCs and an Offshore Monohull Production Vessel) over the last 15 months is described and typical results presented. The importance of these results to the prediction of ship structural durability and their value in ship operation is discussed.
\end{abstract}

\section{INTRODUCTION}

BP Shipping operates a class of five VLCCs built by Mitsubishi Heavy Industries of Japan in the mid 1970s which are now in excess of 15 years old. The authors recognised, about two years ago, an opportunity for developing a strategy to more comprehensively, and more objectively, examine the structural ageing process in this class of tankers. This came about through reflecting on experience gained by close involvement in resolving a number of important technical problems concerning tanker structure since the late 1970 s, and particularly technological development in the Offshore Industry during the $1980 \mathrm{~s}$.

A particular challenge was to establish a calibrated analytical database for these ships, which would assist in identifying practical measures in terms of structural preventative maintenance and/or enhancements, and operational practice, which would improve management of structural failure risk. Of course, the risk cannot be eliminated entirely. Serious structural failure

* Technical Manager, BP Shipping Limited, Harlow, Essex, United Kingdom

** Assistant Technical Manager, BP Shipping Limited, Harlow, Essex, United Kingdom

*** Lead Naval Architect (Development), BP Shipping Limited, Harlow, Essex, United Kingdom

Received 10th JAN 1992

Read at the Spring meeting 12, 13th MAY 1992 can result in fractures in the hull envelope leading to pollution. Two possible fracture mechanisms have been studied, namely brittle fracture arising from peak dynamic loading in the presence of a discontinuity or defect in the structure, and fatigue fracture due to repeated cyclic wave loading. Such a discontinuity may originate from fabrication defects or a fatigue mechanism.

This paper describes the investigations undertaken and the structural management strategy developed to more effectively control the risk of structural failure. These investigations have been undertaken without resorting to a complex risk analysis procedure, which is not considered appropriate at this stage.

The flrst step was to carry out an analytical study of the potential loads that could occur on the ship's structure. Sensitive locations in the structure could then be identified from the resulting stress distribution. Knowledge of these areas then enabled an inspection programme to be developed, such that possible fractures could be detected before they reached critical proportions for rapid propagation and brittle fracture to occur; this formed the second step.

Thus, a pro-active approach has been developed where inspection resources can be concentrated on the most sensitive areas for serious structural failure through a master inspection schedule.

The final step was to implement continuous structural monitoring through instrumentation, designed as a means of correlating the analytical results with full 
scale measurements. A further benefit from this facility is the provision of a means of displaying structural loading to the ship's staff during passage, so that action can be taken to reduce excessive environmental loading on the structure.

Analytical studies commenced in January 1990 and were completed in July 1991.

The key elements of the structural management strategy are shown in Fig. 1.

\section{IDENTIFICATION OF RISK OF FAILURE}

\section{Past Experience}

BP had experienced brittle fracture on a 25,000 TDW product tanker in December 1977 when the ship was 5 years old. This vessel was in a light ballast condition proceeding through the Skaggerak into the North Sea, having discharged in the Baltic.

A small number of large waves were encountered in a short time causing two fractures which originated on the upper deck and continued to propagate through the gunwale and then down the ship's side to the waterline. One fracture occurred at about $1 / 3$ length from the stern on the port side and the second fracture occurred at about $2 / 3$ length from the stern on the starboard side. Rapid action and good seamanship saved the vessel from what would have been almost certain foundering. Examination of the vessel subsequently indicated the presence of notches in the upper deck, which at the time of the incident was at a temperature of $-2^{\circ} \mathrm{C}$. It was concluded that the ship hull girder was subjected to several severe slams as a result of pitching in steep waves, producing longitudinal stresses which, combined with the presence of significant notches and low temperature, led to brittle fracture.

It is worth noting that the upper deck plating was " $\mathrm{A}$ " quality and of a thickness that did not require toughness testing according to Classification Society Rules. Subsequent Charpy testing revealed that the poor ductility of the material contributed significantly to the failure. It is further worth noting that no buckling or permanent distortion of the deck plating occurred.

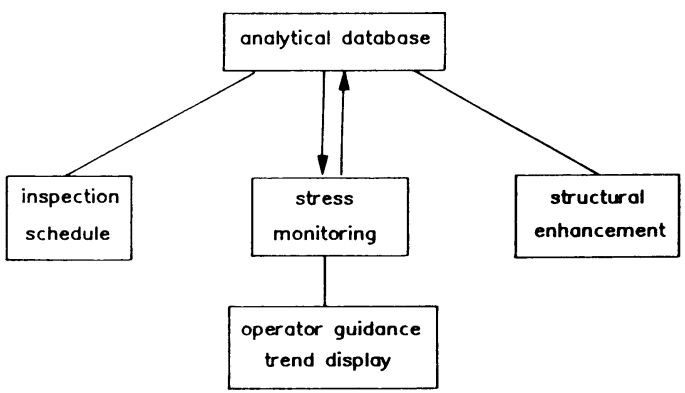

Fig. 1 Structural Management Strategy

\section{New Theoretical Techniques}

This experience led to the investigation of peak stress caused by slamming in the ballast condition. The study at that time focused on assessing the risk of occurrence of slamming and adopting measures to reduce this risk.

An immediate BP Shipping policy decision in 1978 was to fit grade " $D$ " plating to the decks of all future newbuildings.

A new method" had been proposed to investigate vibration of the hull girder in waves and this technique was applied to study the product tanker incident. Satisfactory results from this theoretical investigation provided a logical basis for assessing the effets of slamming performance and structural vibration on the VLCCs.

Following the product tanker investigation, several structural performance assessments incorporating dynamic loading analysis were carried out by the authors between 1986 and 1990 covering oil and gas tankers, a semi-submersible emergency support vessel and an oil production tanker.

\section{Analytical Studies}

Thus, a strategy emerged from the foregoing experience which could be applied to the risk of structural failure in VLCCs. A theoretical investigation into the occurrence of slamming performance would evaluate the sensitivity of the structure to loading from key operational parameters such as speed, wave heading and ballast draught. In addition, the critical crack size necessary to initiate brittle fracture at a given temperature, could be determined for selected locations in the structure and used as a benchmark for inspection criteria. The rate of growth of such a crack would determine the maximum inspection interval that could be tolerated. Further control of the risk could be achieved by continually measuring the actual longitudinal stress on the deck at sea, thus providing immediate warning of severe stress being experienced. Ship's staff could then take appropriate action as described above. Also, feedback could be gained on how much reduction in stress had been achieved through such action. Recording of peak and cyclic stress, and the environmental conditions at the time, would facilitate key correlation of the theoretical studies into structural performance. A time history of cyclic stress frequency and amplitude would enable fatigue damage accumulation rates to be determined more objectively, through cross reference to the analytical prediction. Thus, the idea of a full scale structural monitoring system was conceived about three years ago.

Fatigue studies could be employed to investigate the likelihood of a notch developing at a typical connection detail, which would provide an initiation site for possible brittle fracture.

Fig. 2 illustrates the parameters involved in providing a measure of control of risk of structural failure. 


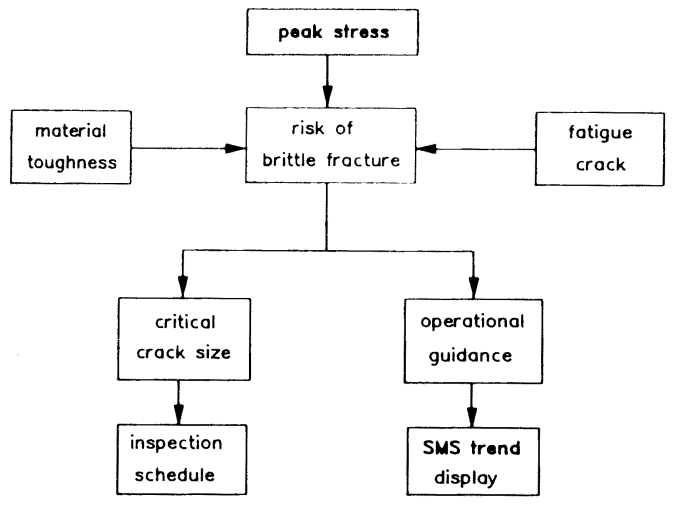

Fig. 2 Control of Risk of Brittle Fracture

\section{ESTABLISHING THE ANALYTICAL DATABASE}

\section{Introduction}

Pulling together the various elements of Fig. 2 provides the core risk assessment procedure. The main analytical processes are:

1. Establish the structural design basis relative to Classification Society Rules and ascertain the sensitivity to corrosion.

2. Complete a wave bending analysis including dynamic loading.

3. Estimate fatigue durability.

4. Evaluate crack growth rates for sensitive locations in the structure through fracture mechanics.

Existing records of corrosion and local structural damage in the class of VLCCs were used as direct input to the above. The results from these activities enabled an assessment of risk of failure to be determined.

\section{Review of the Design Basis}

A thorough appraisal was made of the possible margins in the original VLCC design, relative to Classification Society Rule requirements at the time of build and subsequently during the operating life.

Corrosion scenarios over a 25 year service life were developed for all primary structure in the midbody on the basis of extrapolation of thickness measurements to date, i. e. after 15 years, and experience on other tankers. Linear extrapolation was assumed for this study, but it is recognised that this may be simplistic over such a long period. This simplification was tempered, however, by adoption of corrosion rates at the upper bandwidth of experience and measurements, such that the corrosion levels predicted at the 25 year state are generally considered to be pessimistic. Thus, when individual ships are assessed against these corrosion scenarios, there is a margin for possible variations in the corrosion rates experienced.

Longitudinal scantlings were compared using empirical Rule formulae for the new ship and at the 25 year corrosion condition. Typical results are shown in Fig. 3.
The ratio of actual scantling to the Rule requirement is depicted in Fig. 3 for both plating and stiffener in the midship section. At first sight, values of the actual to Rule scantling ratio appear often to be well below unity after 25 years. This variation is complicated by recent revisions to Rule requirements. For the deck, increased plating scantlings are required, but stiffener scantlings can be reduced. At the bottom shell, the Rule requirements have increased for both plating, and stiffener scantlings. At the mid-depth, no significant changes to the Rules have occurred. A further consideration in the deck plating scantling ratios is the fact that the subject VLCCs were built with a plating thickness of nearly $24 \%$ in excess of the Rule requirement at that time. However, it can be seen from Fig. 3 that this margin would not be sufficient to combat the effects of the 25 year corrosion scenario and still satisfy Rule requirements. It should be noted that this design is fitted with higher tensile steel (AH32) in deck and bottom structure only, which was common practice in the mid seventies.

Primary transverse structure was studied using a Finite Element (FE) approach. Stresses were checked against rule criteria as well as buckling factors of safety. In this study, a three dimensional hybrid FE model of $1 \frac{1}{2}$ centre tank lengths was used for transverse strength assesment. This approach is generically termed "static" since the standard Classification Society Rule structural loading method is used, whereby static tank heads are applied to the internal structure and buoyancy forces to the ship's hull based on a static waterline.

In summary, the review has shown that since this class of VLCC was built in the early seventies, some scantling requirements (i.e. Classification Society Rules) have changed. If the same ships were to be built today, they would have reduced scantlings in some locations. The change in scantlings is believed to represent a better understanding of the loads on, and strengths of, the various structural elements in ships.

In particular, the longitudinal strength of this class of VLCCs as designed in 1974 is about $6.5 \%$ greater than would be required by the 1989 Rules. The result of the

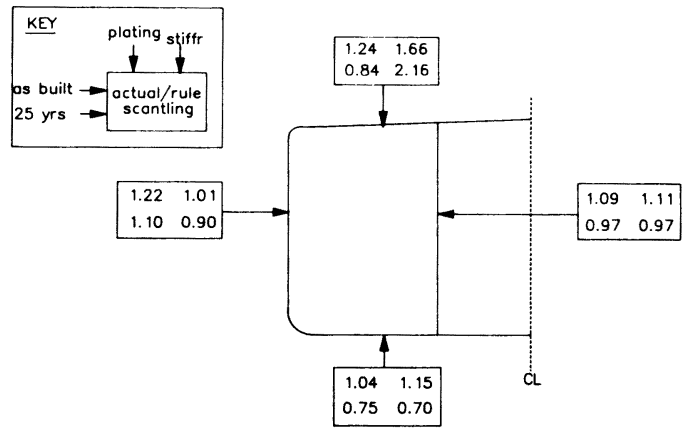

Fig. 3 Effect of Corrosion on Local Scantlings 
slightly greater steelweight present in these ships is that they can theoretically, tolerate a larger amount of corrosion in some locations than was anticipated at the time of their design, without increasing the risk of ductile failures above the level associated with modern ships.

However, there are certain structural elements that, after relatively small amounts of corrosion, would not satisfy present Classification Society Rule requirements. Principally, these are parts of the transverse bulkhead plating and stringers. Typical results for a transverse bulkhead horizontal stringer are shown in Figs. 4 and 5 where the design margins in terms of stress and buckling factor of safety are shown to be below design requirements at the 15 year corrosion condition.

These elements need either to be enhanced to bring them up to standard and provide sufficient margin for corrosion over the remaining life of the ships, or to be monitored to ensure that corrosion does not reduce the scantlings below the acceptable level, as defined in the analytical database. This can be satisfactorily managed through the focused inspection procedure.

The remainder of the structure requires to be monitored to ensure that corrosion does not exceed the levels at which remedial work on the various structural

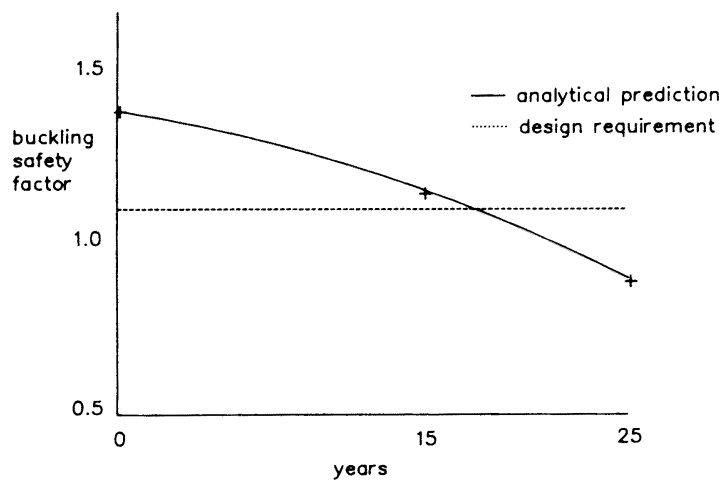

Fig. 4 Effect of Corrosion on Buckling Criteria

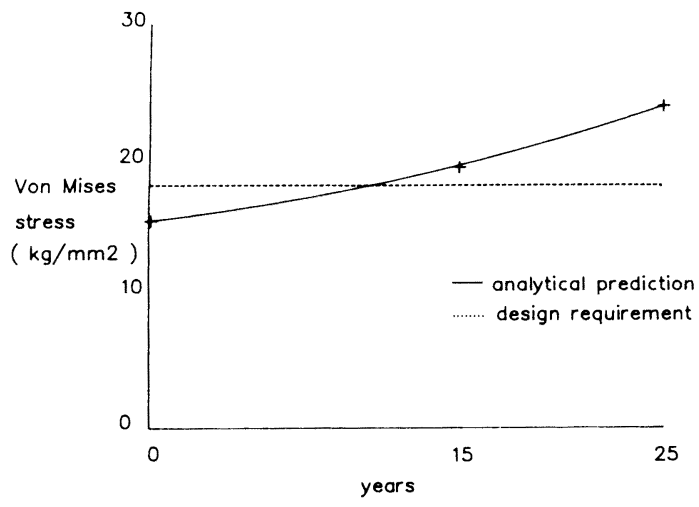

Fig. 5 Effect of Corrosion on Stress elements becomes necessary. Criteria for permissible diminution have been selected based on the results of the analytical work, together with the levels of stress and corrosion that the Classification Society would permit. Account was taken of the various likely modes of failure of the structure, e. g. overstressing, buckling.

The summation of these criteria may be judged to be conservative. However, the analysis has enabled critical locations in the structure to be identified, and sometimes modified, so that the inspection schedule can be realistic both in terms of frequency and extent, compatible with available inspection resources. Areas where potential problems have not been identified by the analytical studies or service history can be satisfactorily covered by Classification Society surveys.

\section{Wave Bending Analysis}

Conventional ship design makes use of either Classification Society formulae, or the simple concept of balancing a ship on a sinusoidal or trochoidal wave, to obtain peak bending moment response.

In the new approach, wave bending response was studied from three aspects:

1. Quasistatic Wave Bending

2. Dynamic Response (linear) of the Hull Girder to Wave Frequency Loading (Springing)

3. Dynamic Response (non-linear) of the Hull Girder to Bow Impact (Slamming)

Quasistatic wave bending analysis makes use of a linear calculation procedure to evaluate wave loading and ship motions over a range of wave periods and wave heading angles. The results were provided in the form of transfer functions which are amenable to carrying out spectral calculations to determine peak and fatigue response of the hull girder. The term "quasistatic" describes the way in which ship motions in the form of global accelerations are used, to statically equilibriate the wave loads which are applied to a finite element beam model of the hull girder.

Wave excited resonant hull vibration, i. e. springing, was studied using a frequency domain method where the ship was modelled as a beam on elastic supports. Similar beam element models to the quasistatic analysis were used, the main difference being inclusion of added mass as a structural mass, rather than hydrodynamic loading. Added mass is frequency dependent, and was applied to the vessel as a series of point masses aranged along the length of the hull. Hydrodynamic stiffness due to waterplane area was modelled as a distribution of linear spring to ground elements.

Slamming analysis used a non-linear hydrodynamic approach, where the ship response was calculated taking into account changes in hydrodynamic stiffness and added mass, due to immersion and emergence of the hull sections. Impact slam theory ${ }^{2)}$ was used to determine a time history of loading for application to the dynamic structural model. The quasistatic analysis model was used, but added mass appropriate to the relevant load. 
ing condition and hull girder natural frequency were included in the structural mass modelling.

Results of these studies indicated that peak vertical wave bending moments occurred in the ballast condition, which followed trends from earlier investigations. Vertical and horizontal wave bending were studied over a range of wave period and heading angles. As the heading angle changed from head seas to beam seas, the peak vertical bending moment decreased and horizontal bending moment increased. At the same time, the period at which the peak response occurred changed. These effects, when considered in conjunction with environmental wave data and voyage route wave headings, were found to be important for calculating fatigue damage due to wave bending. Whilst the magnitude of the horizontal bending moment was low relative to the vertical component, phasing of the two loading mechanisms was very important when evaluating the combined effects of vertical and horizontal bending, particularly for locations close to the extreme fibres of the section, such as bilge and deck edge. A wave heading angle of $120^{\circ}$ was found to give a peak combined stress in these locations was a result of these two components being in phase. This combined stress is important when calculating fatigue damage which can be considered proportional to the cube of the stress range.

The importance of springing to the wave only bending moment component was found to be small outside the critical resonant period of 2.08 seconds in light ballast and 2.42 seconds in loaded condition. Results were found to compare favourably with those quoted ${ }^{1,3)}$. It was clear that springing response would contribute significantly to fatigue loading.

The relative sensitivity of the response of the hull girder in terms of peak stress and fatigue for the three components of wave bending, springing and slamming is summarised in Table 1.

This summary is intended to give an overall impression, and it is recognised that the effect of trade route, draught forward and speed can change these relative comparisons. In the case of fatigue loading, these sensitivities are quantified in the next section.

Slamming response had a major contribution to the peak wave bending response in ballast condition. For any given wave period a wave height was identified below which impact slamming would not occur. As regular wave period increased, slamming did not occur until a critical period was reached. Peak slamming bending moments were found to rise to a maximum at

Table 1 Relative Sensitivity of Hull Girder Response

\begin{tabular}{|l|c|c|}
\hline \multirow{2}{*}{$\begin{array}{l}\text { HULL GIRDER } \\
\text { BENDING COMPONENT }\end{array}$} & \multicolumn{2}{|c|}{ RELATIVE SENSITIVITY } \\
\cline { 2 - 3 } & PEAK STRESS & PATIGUE \\
\hline WAVE BENDING & MODERATE & HIGH \\
\hline SPRINGING & LOW & MODERATE \\
\hline SLAMMING & HIGH & LOW \\
\hline
\end{tabular}

a period where vessel pitch motions were high, i. e. about 11 seconds, and then reduce to much smaller values as the wave period and length increased. Sensitivity of these results to speed and draught forward was assessed. Critical slam curves could then be defined based on regular waves, for exceedance of pre-determined bending moment criteria. An example of these critical slam curves is given in Fig. 6 .

These curves represent the wave period and height that will cause the onset of slamming in head seas and in light ballast condition. Further curves can be derived for depicting the likelihood of excessive slamming such that design criteria are exceeded. Both of these curves have been subsequently developed into a format suitable for the structural monitoring system trend display module, so that ship's staff are given warning of the likelihood and severity of slamming.

The effect of two typical VLCC trade routes on slam response was investigated for both light and deep ballast draughts. The number of slam occurrences per year were found to be negligible for the Japan/Gulf route in either condition whilst for the North West Europe (NWE)/Gulf route, the number of slam occurrences increased dramatically between deep and light ballast conditions.

Sensitivity of the analysis to damping was found to have a large influence on the results. Full scale measurements using the structural monitoring system will enable a better assessment of damping to be undertaken.

\section{Fatigue Durability}

The ships are in excess of fifteen years old and all the structural elements have a notional fatigue life, some of which has been used up. It is not possible to calculate exactly the fatigue life of a specific structural element in a particular ship as there are too many variables. Primary influences are the environmental loading imposed during operation and the amount of corrosion which has taken place. However, by making certain assumptions and comparing calculations of fatigue with known fractures, it is possible to make reliable estimates of whether a particular element has high, medium or low fatigue durability. Structural elements with fatigue lives which could possibly be used up

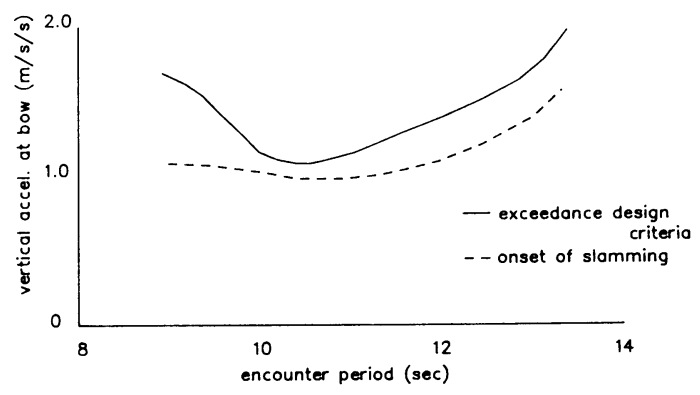

Fig. 6 Critical Slam Curves 
within 25 years have been identified.

Experience with the techniques of fatigue assessment for offshore structures ${ }^{4}$ was adapted to ship structural design where hull girder bending due to wave action is a primary fatigue mechanism.

Fatigue durability of deck and bottom structure details was assessed against the design requirement determined through analysis. Where low durability indicated a possible initiation site for a crack, the time for growth of such a crack to a critical size necessary to induce brittle fracture was then investigated.

Fatigue prediction for new designs or existing ships must take cognisance of actual service conditions as far as is possible. The concept of a fatigue screening mothod $^{5)}$ for discrete sea areas, based on a fatigue vulnerability factor, is a logical development. It follows that where ships operate all or most of their lives on a dedicated trade route, it will be possible to more objectively design newbuildings for fatigue durability or evaluate the risk in existing ships. Success and confidence in the analytical predictions will, of course, be governed by the availability of accurate peak and cyclic environmental loading data through full scale monitoring.

A second important fatigue mechanism arises from wave action on the side shell, where repeated wave crest/trough passage can cause a fluctuating stress, possibly augmented by ship motions.

Fatigue analysis of local details on the subject ships was carried out at the following locations:

1. Centreline girder bracket connection to transverse bulkhead

2. Upper cross tie outboard connection to side shell

3. Deck longitudinal connection to transverse bulkhead

4. Bottom longitudinal connection to transverse bulkhead

The analysis method used was deterministic. Concentrations were identified from a local finite element analysis of the detail connection, under the loadings of a static wave crest and trough to derive a stress range. Derivation of a long term distribution was then applied to standard fatigue $(\mathrm{S} / \mathrm{N})$ data, which relates stress range to number of cycles to failure, to obtain the cumulative fatigue damage ${ }^{4)}$. Location 1 had already shown distress in service and the fatigue analysis was used to assess the benefit in fatigue performance of modifications to the detail arrangement.

Location 2 also had shown recent distress in service. The cross tie connection is 4 metres below the loaded waterline. Sensitivity of side shell longitudinal stiffener connection details to fatigue failure was experienced on a previous VLCC class built in the early 1970s. The lessons learnt from these failures, after 7 years in service, were that the type of longitudinal stiffener and bracketing geometry was important to fatigue durability. The current VLCC design has a fabricated angle bar which enabled the pillar stiffener from the transverse web to be butt welded to the angle bar face plate.

The subject VLCC design has, however, only suffered distress at the upper cross tie connection to the side. shell and not at the normal web frame connection clear of the cross ties. Finite element analysis of this connection detail using simplistic static wave loading indicated high fatigue sensitivity, but this was very localised at the elements representing the stiffener bracket heel and toe. An improved method of assessing fatigue durability was developed using fracture mechanics elements to represent fracture propagation in different members under the action of fluctuating side shell pressure derived from voyage route wave data. This is discussed in the next section.

Locations 3 and 4 were investigated for sensitivity to fatigue fracture leading ultimately to a brittle fracture initiation site. Initially, the deterministic method was used which yielded fatigue lives below 25 years for both locations.

A comprehensive fatigue analysis was carried out using service voyage data for the Gulf/Japan and Gulf/ NWE voyage routes. Sea state data was processed for each route to provide voyage-specific environmental conditions. Environmental data ${ }^{6)}$ was obtained for sea areas applicable to each route. For each sea area, inhouse records of course headings and time on each course was calculated. By using the environmental data relating to sea state, occurrence and direction for each sea area, an equivalent sea state scatter diagram for each voyage was calculated. To enable a comparison to be made between the voyage routes and ship speeds, a typical hull connection detail at the deck edge was chosen. Stress ranges were derived from longitudinal bending moments for both vertical and horizontal components. Contributions of wave bending for both vertical and horizontal components, springing, and slamming were investigated separately and then combined.

Considering wave bending only, a decrease in speed over the range examined showed an unexpected increase in fatigue damage. This effect was investigated and found to be due to the relative shapes of the transfer functions and the wave spectrum.

Another significant result from the wave bending fatigue study was higher damage arising in following seas than in head seas. Further examination revealed the peak response in following seas as being closer to the densest part of the fatigue loading curve (represented by number of occurrences multiplied by the wave height cubed) than for head seas. This effect is shown in Fig. 7.

The effect of springing on fatigue damage was found to be most significant in head seas $\left(180^{\circ}\right)$ and up to $30^{\circ}$ off the bow when the natural hull girder period is excited. The increase in fatigue damage was greater in the ballast condition than in the load condition. This is as expected, since stress response is greater for the 


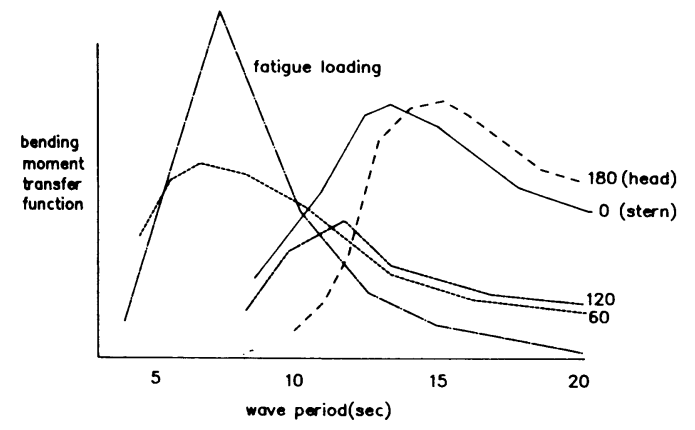

Fig. 7 Effect of Wave Heading on Bending Responses

ballast condition. Since springing response is greater at higher speeds, a reduction in speed will reduce fatigue damage.

Slamming occurrence in the ballast condition was predicted to increase the fatigue damage dramatically, this being even more prevalent at higher speeds. Synthesis of fatigue damage accounting for the summation of these components at three speeds is shown in Fig. 8 for the Gulf/NWE route in ballast and load conditions.

The above results have been derived using a spectral fatigue method assuming uni-directional seas for each wave heading angle. If wave spreading is taken into account, then the above fatigue damage for the ballast condition is further increased. Wave spreading effects are important when correlating full scale measurements with theoretical predictions.

The elements where cracking has occurred and where the analytical work predicts low fatigue lives on these particular VLCCs are, as previously stated, the longitudinal connections in way of the upper cross ties and the longitudinal centreline girder brackets. In addition, low fatigue lives were predicted at the deck and botton longitudinal connections to the transverse bulkheads. No cracking has yet been found in the upper deck area although access to the upper connection is impracticable. Access has been addressed in the structural en-

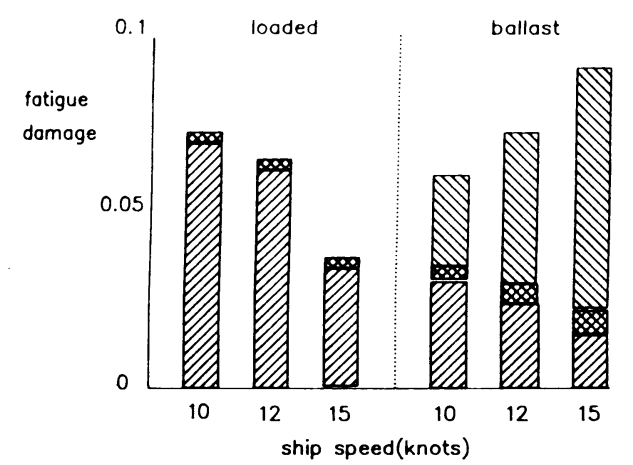

$\nabla$ wave bending $\mathbb{B}$ springing $\Delta$ slamming

Fig. 8 Fatigue Damage Summary over a Gulf/NWE Route hancement programme. First indications of cracking are now being found at the bottom connection after 15-17 years. The importance of phasing of horizontal and vertical hull girder bending as well as side shell pressure loading has been identified and taken into account in determining the repair action required.

Cracking has also been found at the trasverse bulkhead stringer bracket toes. Fatigue calculations were not carried out at this location, but the static analysis indicated very high stresses, and comparison was made with a fatigue analysis carried out on a recent newbuild product carrier. Other elements identified as potentially having low fatigue lives by considering stress levels from the static analysis were the transverse bracket toes.

Locations where cracking has already been found on the ships have been enhanced. Other critical areas identified from the analysis but not structurally modified, will be included in the inspection schedule.

Observation of ship's staff on this class of ships indicates that longitudinal bow impact loading occurs in the loaded condition which has not been quantified in this study.

\section{Fracture Mechanics}

The dynamic wave bending analysis has shown that there is a finite risk that the vessels can experience very high loads due to slamming of the bottom forward in waves whilst in ballast, as previously stated. The risk of damage can be minimised by operating the ships in a way that considerably reduces the possibility of such slamming occurring. The study has investigated variations in heading, speed and loading condition to reduce the likelihood of slamming. The measures to take depend upon the sea-state.

There are two possible failure modes caused by high peak loads. One is that the hull will take up a permanent distortion with buckled plating and possibly tearing causing loss of watertight integrity. The other is that, under a critical combination of circumstances, brittle fracture could suddenly occur, also leading to loss of watertight integrity.

Determination of the critical crack size was carried out using fracture mechanics techniques. In this case, established UK civil engineering techniques ${ }^{7)}$ were used. Important input to this work was the properties of the ship's steel plating. Initially, as no data was available from specimens from the ships, the UK Welding Institute provided standard data. Additional guidance ${ }^{8)}$ was used.

In conventional deterministic fatigue studies, problems had been encountered with interpretation of stress range results. This led to development of a new technique of blending fracture mechanics elements within a detailed finite element model. These elements were inserted at fatigue sensitive locations in order to calculate and compare crack growth rates. The conventional $\mathrm{FE}$ modelling approach relies heavily on interpretation of 
stress results at a geometric discontinuity, which often is a right-angled corner. The mesh density can have a dramatic effect on the calculation of local stress levels which theoretically are infinite at such a discontinuity. Use of fracture mechanics elements enabled this difficult interpretation to be avoided. A crack-like defect was modelled using specially formulated elements and a crack energy release rate was calculated by the analysis program for a given loading condition. From these results, stress intensity factors were derived which could be applied to a standard crack propagation calculation using the Paris Equation.

Application of this method to the original upper cross tie outboard connection to the side shell, indicated a high rate of crack growth from the tripping bracket heel, as was found from ship inspections. The benefit from addition of a backing bracket was analysed and found to reduce the crack growth rates to an acceptable level. Studies of the longitudinal extent of wave damage at this level were used to specify the repair locations. It was concluded that this method provided a more meaningful assessment of fatigue durability.

The upper deck is considered to be the part of the main hull most sensitive to fracture propagation since this area, and the bottom shell, experience the highest dynamic loads from hull girder bending, particularly in the ballast condition. The deck may experience very low temperatures, depending on ambient conditions, which can significantly affect the material properties of the deck plating. In addition, the number of welded connections to the deck for pipe racks, guard rails etc, mean that there is a greater likelihood of a crack-like defect being present.

Fatigue crack propagation from the toe of the bulkhead stiffener bracket to the upper deck longitudinal stiffener was investigated.

Cyclic stress loading from all the wave bending components was applied over the two trade routes. Assuming that the vessel was operated $100 \%$ on the NWE/ Gulf trade route, then it was estimated that a detectable fatigue crack of $15 \mathrm{~mm}$ would propagate to the deck plating in less than 10 years in loaded condition, and almost half this time in ballast condition.

Having determined the time for the crack to propagate to the deck, the risk of brittle fracture was assessed. Critical crack size was estimated, taking account of three major influences: fracture toughness, temperature and stress level. The fracture toughness index $K_{1 \mathrm{c}}$ was determined for the AH32 steel fitted to the upper deck. The level of total stress would be dependent on the externally applied stresses (i.e. wave bending responses) and also the residual stress arising from initial fabrication. A factor of 2 could be applied to the total stress to account for possible geometry induced stress concentrations at the initiation site. Residual stresses could equate to the yield stress of the material giving a very pessimistic evaluation of critical crack

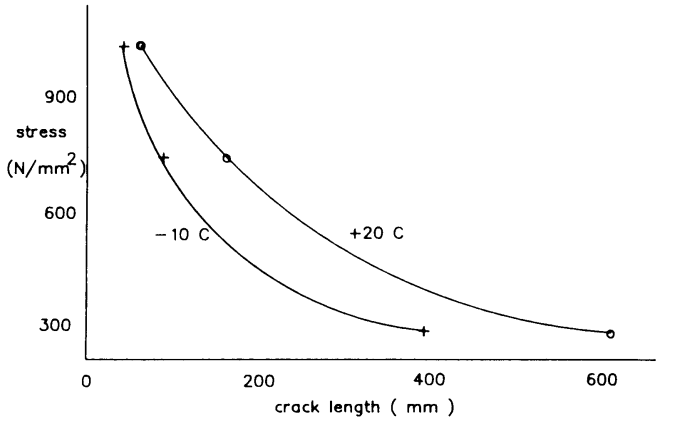

Fig. 9 Stress/Temperature Effect on Critical Crack Size

size. The relationship between critical crack size, stress and temperature is shown in Fig. 9.

A more realistic assessment of total stress could be built up from a dynamic wave stress of yield, together with a factor of 1.5 for local geometry, and negligible effect of residual stress, which would normally be compressive. It is recognised that these estimates are simplistic since they assume an elastic type of response to extreme loading. The actual ship response would prob. ably contain plastic behaviours which would be generally beneficial since some of the energy imparted to the hull can be absorbed by permanent deflection.

Estimation of the rate of growth of a fatigue crack at the deck and bottom longitudinal connections to transverse bulkheads show that the frequency of inspection required depends upon the inspection method used. If visual inspection is used then the frequency will need to be about once per year to avoid a visibly detectable crack growing into the plating.

If non-destructive testing (NDT) methods (e.g. Magnetic Particle Inspection) are used then the inspection frequency can be much lower as the crack can be detected at a very much smaller size. The crack growth rate calculations also show, depending upon the size of the crack, whether it will be necessary to repair cracks immediately, or whether it will be safe to wait until the next programmed docking.

\section{STRUCTURAL MANAGEMENT STRATEGY}

\section{Summary}

From the foregoing the authors conclude that the risk of serious structural failure can be managed effectively in these ageing ships by adopting the following mea. sures :

i) Enhancing deficient areas of the structure:

a) In light of previously discovered distress

b) Pro-actively using modern structural design tech. niques

ii Setting better focused criteria for structural maintenance :

a) Based on permissible corrosion levels 
b) Based on permissible crack sizes

iii) Implementing an inspection schedule with appropriate staff training.

iv) Providing permanent means of access to selected critical areas which are normally difficult to inspect in service.

v) Providing guidance to ships' staff for the minimisation of structural damage:

a) By using on-board measurements and displays

b) By limiting loading conditions

c) By limiting speed and heading in waves

vi) Obtaining feedback from ships' structural performance in operation to reduce uncertainties :

a) Through inspection and non-destructive testing (NDT)

b) From structural monitoring system data

This study has focused on using theoretical methods to determine the critical length of a crack to initiate brittle fracture. This key information has been used to determine inspection location, frequency and detection method. An inspection programme has thus been developed based on detection of a crack before the critical size is reached.

All these factors were distilled to form a structural management strategy for controlling the risk of structural failure to an acceptable level for the remaining life of these ships. The core elements are:

a) Establishing an analytical database

b) Implementing a focused structural inspection programme

c) Implementing a structural enhancement programme

d) Installing on-line structural monitoring for guidance to ship's staff

\section{Inspection Programme}

An inspection programme was devised to meet the following two objectives:

i) To facilitate comparison of actual corrosion levels with predictions to ascertain whether to proceed with the planned structural enhancements based on the analytical study.

ii ) To confirm the general state of the structure in order to compare with the assumptions made in the analytical work.

The inspection was primarily visual and extensive ultrasonic thickness measurements were specified where appropriate.

\section{Structural Monitoring}

A structural monitoring system was designed to meet two fundamental objectives:

a) To measure hull structural responses to the environment for use in correlating with analytical predictions.

b) To provide on-line guidance to ship's staff on exceedance of preset stress thresholds in severe weather and enable tactical decisions to be made in ship operation.

The layout of the system is shown in Fig. 10.

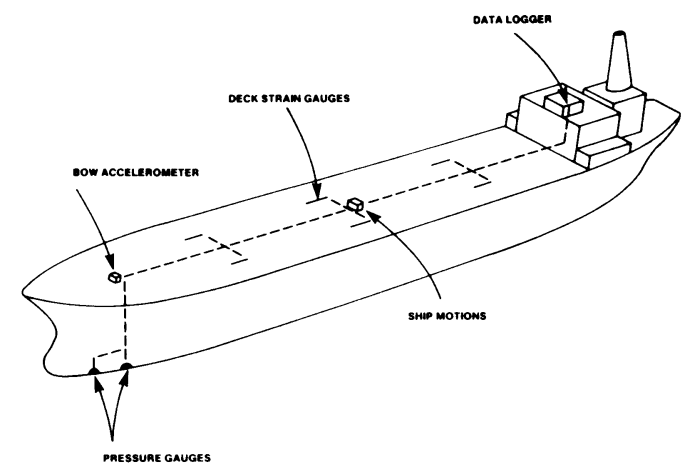

Fig. 10 Layout of Structural Monitoring System

Primary hull girder bending was measured by means of three pairs of long base strain gauges mounted on the deck over the longitudinal bulkheads at midships and the $1 / 3 \mathrm{~L}$ and $2 / 3 \mathrm{~L}$ locations approximately.

Pressure transducers have been fitted on the bottom shell forward to detect the incidence of a forefoot slam for correlation with the hull girder response measured by the deck strain gauges. A bow accelerometer was provided for correlation of bow emergence with analytical predictions. Ship motions in roll, pitch and heave axes were measured for general information on labouring of ships in heavy seas.

A data logger module and a trend display module were located on the Navigating Bridge. Data is recorded via two devices, the twelve channel data logger and the SHIPLOG which records environmental and ship condition data input manually by the officer of the watch. The data logger samples deck strain gauge and accelerometer readings at $8.33 \mathrm{~Hz}$ and bow pressures at $50 \mathrm{~Hz}$ which is stored on an EXABYTE tape, with a capacity of 3 Gigabytes. The SHIPLOG data is input manually each watch and stored on a conventional $31 / 2$ inch floppy disc. These discs and tapes are returned from each load/discharge port to Head Office for analysis.

The prototype was fitted to the BP Oil Production Vessel SEILLEAN in February 1990. This vessel is a tanker which can be positioned over an oil well by use of dynamic positioning. A structural assessment of this vessel had been carried out during the building stage and had highlighted some areas requiring enhancement due to high sensitivity to fatigue damage. The structural monitoring system was fitted to keep watch on structural performance in UK North Sea operation.

Similar structural monitoring systems were fitted to the VLCCs BRITISH RANGER in April 1990 and BRITISH RESOLUTION in November 1990. These two vessels form the prime data gathering source for the whole class of VLCCs for correlation with the analytical predictions. Trend displays were fitted for on-board guidance of exceedance of design strength criteria. 
Display of bending moment plotted against time provided on-line guidance of trends of variation against an upper design limit, a "red line". Red lines were set initially at the rule design still water and wave stress on separate display pages, but will be adjusted following analysis of the structural performance measurements and as corrosion data becomes available for each ship. Guidance on the likelihood of slamming in light and deep ballast conditions was displayed in terms of bow acceleration and wave period, relative to two sets of critical slam curves derived from Fig. 6 above.

A further two vessels in the class were fitted with a reduced system intended primarily for on-board guidance with only limited data recording facilities. These systems were fitted to the BRITISH RELIANCE in November 1991 and BRITISH RESOURCE in December 1991. The remaining ship of the class, BRITISH RENOWN, will be fitted with a reduced system in April 1992.

Being prototypes, equipment teething problems have been experienced, primarily in the waterproofing of the deck transducers and in the data recording system. 1991 has been a busy year in system maintenance and general improvements to ensure higher reliability in the overall system.

Specialised data analysis software has been developed to manage the large volumes of data being received back in Head Office. Inevitably, a lag developed in analysis, whilst such software was developed and a considerable "catching up" period was necessary. Substantial effort has been put into explaining to ship's staff how the displays can be used to improve their knowledge of structural performance in a seaway and hence improve safety of ship operation.

\section{Structural Enhancement}

The design basis section of the analytical studies provided insight into the areas of the structure sensitive to corrosion, based on Classification Society Rule requirements and taking account of direct calculations using finite element modelling. The static loading FE model was subjected to three corrosion scenarios; as built, actual 15 year condition and projected 25 year condition. Safety factors in stress and buckling against rule criteria were then calculated. Where safety factors were already close to, or could foreseeably go below these criteria, action was planned to restore the scantlings to the necessary standard.

This did not always mean replacing the structure to the as built scantling, since in some cases the original factors of safety were very high. For locations with low factors of safety in buckling, a combination of additional stiffening and plating renewal was employed, depending on the local structural arrangements. These measures were aimed primarily at the horizontal girders which were very sensitive to the corrosion scenarios. Areas of the structure which were investigated for fatigue were tested for sensitivity to the corrosion scenarios. Modified structural arrangements were designed for the upper cross tie connection to the side shell for improved durability.

When each individual ship corrosion data was obtained through inspection prior to dry-dock, the appropriate structural enhancement could be planned for that particular ship, to satisfy the safety factor criteria.

The overall effect of these corrosion scenarios on midship section modulus is shown in Fig. 11 where the design modulus is compared with the Rule requirement at that time. The predicted reduction in modulus over 25 years is plotted relative to the Rule requirement, which has reduced over that time period. The actual modulus of the first VLCC inspected, using corrosion data given in Table 2, is shown at the 15 year stage where it can be seen that the values lie very close to the Rule requirement.

\section{PROGRESS IN IMPLEMENTATION OF THE STRATEGY}

\section{Structural Inspection}

The focused structural inspection pogramme was initiated prior to the first VLCC being dry-docked in November 1990.

The levels of corrosion found on the structure were generally less than the levels assumed for the analytical work at the 15 year age point. There were local areas where the corrosion was higher, however. Tables 2 and 3 provide a comparison between actual corrosion rates and the predicted state at 15 years.

The amount of variation from the assumed 15 year levels of corrosion depended upon the location and type

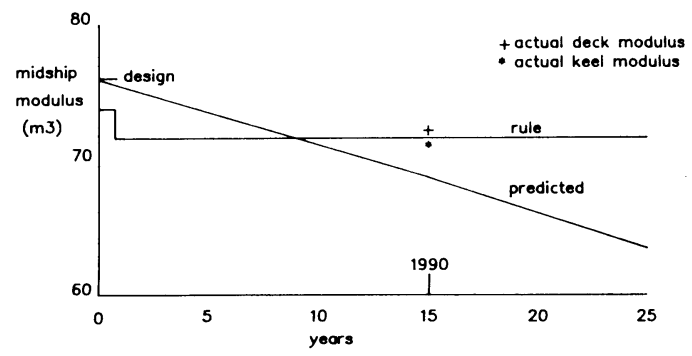

Fig. 11 Effect of Corrosion on Midship Section Modulus

Table 2 Corrosion of Longitudinal Members

\begin{tabular}{|c|c|c|c|c|}
\hline \multicolumn{5}{|c|}{ PERCEATAGE RBDUCTION ON DESIGN THICKNESS } \\
\hline \multirow{2}{*}{ LOCATION } & \multicolumn{2}{|c|}{ PLATING } & \multicolumn{2}{|c|}{ STIFFENRRS } \\
\hline & MEASURED & PREDICTBD & MEASURED & PREDICTED \\
\hline DECK & 6 & 10 & web 2 & 5 \\
\hline SIDE SHELL & 4 & 5 & $\begin{array}{cc}\text { web } & 4 \\
\mathrm{f} / \mathrm{p} & 2\end{array}$ & $\begin{array}{r}10 \\
5\end{array}$ \\
\hline BOTTOM SHELL & 10 & 10 & $\begin{array}{ll}\text { web } & 7 \\
\mathrm{f} / \mathrm{p} & 3\end{array}$ & $\begin{array}{r}5 \\
10\end{array}$ \\
\hline $\begin{array}{l}\text { LONGL } \\
\text { BULKHEAD }\end{array}$ & $\begin{array}{l}4 \\
5\end{array}$ & $\begin{array}{r}5 \\
15\end{array}$ & $\begin{array}{l}\text { web } 4 \\
\text { f/p } 2\end{array}$ & $\begin{array}{r}10 \\
5\end{array}$ \\
\hline
\end{tabular}


Table 3 Corrosion of Transverse Web Frames

\begin{tabular}{|l|c|c|c|}
\hline \multirow{3}{*}{ PERCERTR } & \multicolumn{2}{|c|}{ MEASURED } & PREDICTED \\
\cline { 2 - 4 } & CEATTR TK & WING TR & CEMTRB \& WING TKS \\
\hline WEB PLATING & 7 & 4 & 5 \\
\hline $\begin{array}{l}\text { HORIZONTAL } \\
\text { FACE PLATE }\end{array}$ & 4 & 2 & 10 \\
\hline $\begin{array}{l}\text { CURVED } \\
\text { FACE PLATE }\end{array}$ & 4 & 2 & 10 \\
\hline $\begin{array}{l}\text { VERTICAL } \\
\text { FACE PLATE }\end{array}$ & - & 2 & 5 \\
\hline
\end{tabular}

of structural element. For example, the deck plating was generally corroded to about half the assumed level, whilst the bottom had generally corroded to about the assumed level. These average values cover large variations between locations. The overall corrosion levels assumed for the analytical scenario were intentionally pessimistic for longitudinal materials and this was generally confirmed through inspection data, the main exception being in the stringers on the transverse bulkheads in the centre tanks.

In addition to corrosion, the inspection covered those areas where the analytical studies had identified a possibility of buckling and cracking. No buckling was found. In the main, corrosion had not proceeded far enough for buckling to be likely. The areas where it was expected to become a problem as corrosion proceeded, i. e. the stringers, cross ties and centreline girder, were included for selective renewal/stiffening through the structural enhancement pogramme.

Cracking in certain locations had been identified in previous structural inspections. These were:

1. Centreline Girder Bracket to Web Frame

2. Horizontal Stringer Toes at Longitudinal Bulkheads

3. Upper Cross Tie Outboard Bracket Connection to Side Shell Longitudinal

These areas were re-inspected and a further two cracks discovered in way of the upper cross ties. As previously stated, all these locations correlated with the analytical predictions as being potential sites for fractures.

The huge volume of data generated from thickness measurements and visual inspection is currently being stored on a database for the individual ship for comparison at future inspections.

\section{Structural Enhancements}

The structural enhancement programme for the first ship needed to be prepared before all the analytical studies had been fully assimilated. Some of the enhancements needed to be implemented only if corrosion in the relevant areas showed that either now, or in the future, the previously described criteria would not be met. Fig. 12 provides a keyplan of the locations for enhancement.

In addition, permanent access arangements were installed to enable future inspections to adequately reach critical points under the deck head and in way of the

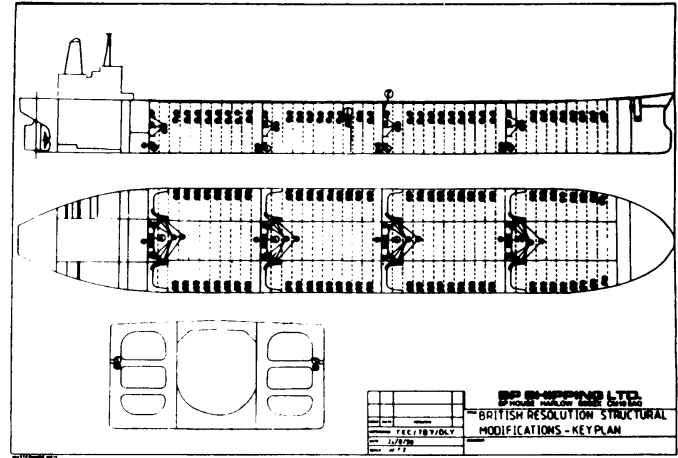

Fig. 12 Keyplan for Locations for Enhancement

upper cross ties. The deck head connections were previously inaccessible without staging : the upper cross ties required rafting.

It was found to be necessary to proceed with all the planned structural enhancements on the first VLCC with the exception of some minor steel inserts on the upper stringers in the wing tanks.

An example of one of these areas for enhancement for the first VLCC in the programme is shown in Fig. 13.

Renewal of plating at the corners of the radiused face plates were due to erosion of design margins in stress, whilst deficient buckling performance necessitated renewal of plating and the addition of tripping brackets on the stringer brackets at the longitudinal bulkhead in the wing tank.

\section{Structural Monitoring}

Analysis of the on-board measurements has been directed at correlation with theoretical predictions of structural performance, as described in earlier sections. Specifically the analysis was focused on providing the following :

1. Fatigue damage accumulation by using a "rainflow" method for counting stress reversals. This will be used to check the theoretical fatigue life prediction in sensitive areas of the structure. Phasing of the vertical and horizontal bending fatigue mechanisms can be investigated from the six deck strain gauges.

2. Prediction of ultimate stress occurrence over the projected ship life. Such a prediction will also enable a check on current newbuild design criteria.

3. Peak stress evaluation against design criteria, particularly in the ballast condition through detection of slamming occurrence and identification of high frequency structural response. Such information is tested against the analytical data and the red line design criteria. A possible revision of the red line can then be made by software to the on-board trend display.

4. Evaluation of damping from slam occurrences to improve prediction of dynamic bending response.

The analysis process is shown schematically in 


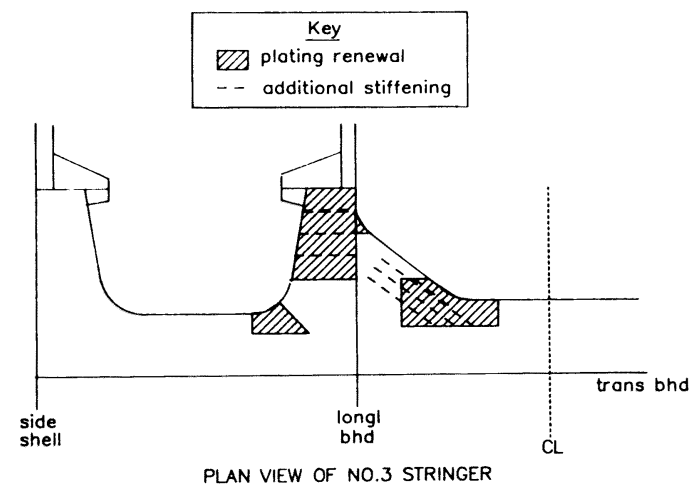

Fig. 13 Typical Enhancement of Transverse Bulkhead Stringer

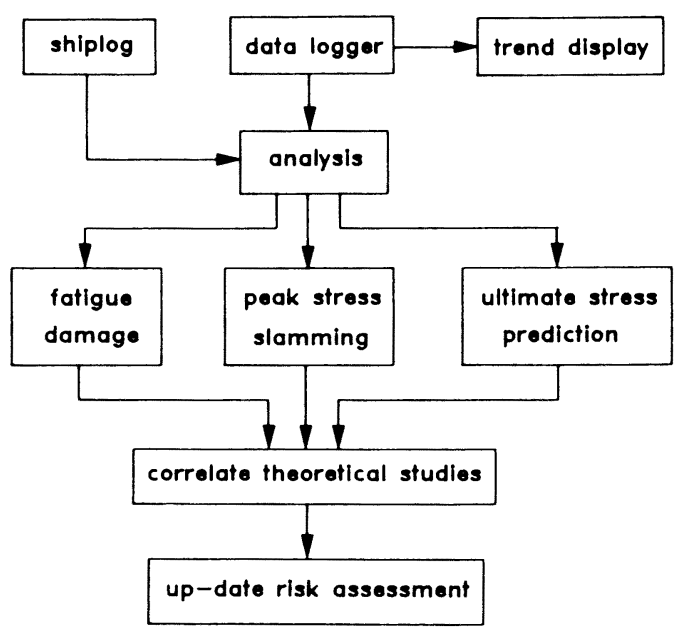

Fig. 14 Analysis of Full Scale Data

Fig. 14.

Preliminary results from the analysis have revealed some interesting features:

1. Slamming in the ballast condition has been detected on many occasions. A fore foot pressure trace during a slam is shown in Fig. 15.

2. Slamming stresses so far measured have been low.

3. Springing of the hull girder has been detected,often associated with the slamming.

4. Wave bending stresses measured approximate to the analytical predictions for the loaded condition.

5. Ultimate stress predictions to data do not show values above Classification Society Rule criteria.

6. Fatigue life calculations have been carried out on stress cycle measurements amidships for one VLCC over 12 months operation. Against a G class detail, a life of 12 years is predicted. Comparison with analytical fatigue prediction is difficult, since the trading pattern and history of the ships is so varied. However, initial indications are that the theoretical

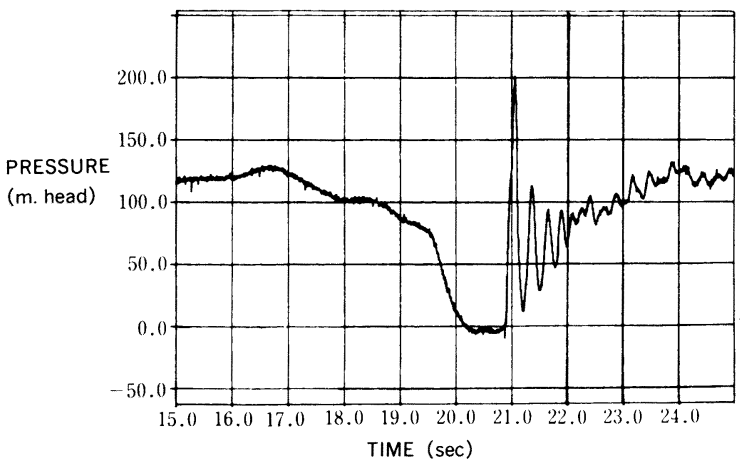

Fig. 15 Pressure Time History

prediction of fatigue life is lower than that calculated. This is to be expected, as some of the assumptions used in the theoretical analysis have been intentionally pessimistic. As further postprocessing of full scale data is carried out, it will be possible to better quantify the degree of pessimism apparent in the theoretical prediction. An example of the rainflow calculation is shown in Fig. 16.

7. Operational measures taken in heavy weather, such as reduction in speed or change in wave heading, have been quantified in terms of structural response.

\section{CONCLUSION}

An important outcome from the work undertaken is the realisation that each ship develops its own unique "signature" in structural performance terms, even though it may start life as one of an identical class. However, through a combination of analytical processes, inspection and operational control, the risk of structural failure can be managed. The approach as described has utilised considerable manpower and cost. The authors consider, however, that the developed strategy will result in better structural risk management through better focus on sensitive locations. The steelweight of a VLCC is around 30,000 tonnes. Experience to date with this approach shows that as little as 100 -150 tonnes of steel objectively replaced/enhanced, can offer better technical value than 10-20 times that amount randomly renewed.

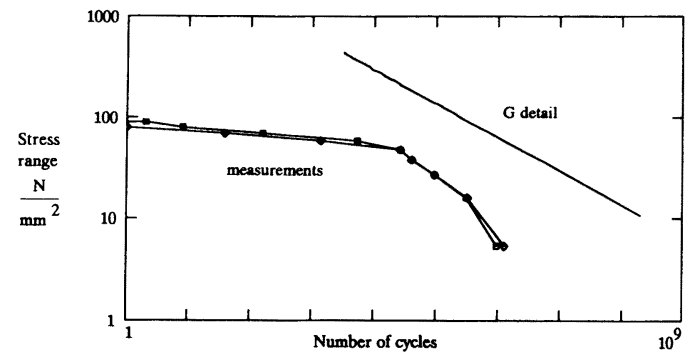

Fig. 16 Fatigue Life Prediction 
The iterative process continues, however, and through our strategy any significant changes in ageing characteristic identified through accelerated corrosion, fatigue cracking etc will be evaluated and appropriate action taken.

Finally, this paper summarises the investigative, and to an extent imaginative, work that has taken place in BP over the last $10+$ years. The authors hope that the progress and experience to date will be of interest to all sectors of the Shipping Industry, at a time when the issue of how to more effectively manage the structural ageing process on VLCCs is being widely debated.

\section{ACKNOWLEDGEMENT}

Special thanks is given to the valuable external support the authors have had to date, particularly from Mitsubishi Heavy Industries Ltd, Atkins Oil \& Gas Engineering Company Ltd and Ship \& Marine Data Systems Ltd, without whose tenacious approach our objectives would not have been met.

Thanks is also due to the continuing support and enthusiasm of our colleagues in BP, who have been a constant source of encouragement.

\section{REFERENCES}

1) Bishop, R.E.D. and Price, W.G., "A Unified Dynamic Analysis of Ship Response to Waves",
Transactions of the Royal Institution of Naval Architects, Volume 119, 1977

2) Bishop, R. E. D., Price, W. G. and Tam P. K. Y., "On the Dynamics of Slamming", Transactions of the Royal Institution of Naval Architects, Volume 20, 1978

3) Goodman, R. A., "Wave Excited Main Hull Vibration in Large Tankers and Bulk Carriers", Transactions of the Royal Institution of Naval Architects, Volume 112, 1979

4) "Offshore Installations: Guidance Notes on Design, Construction and Certification", Document published by the United Kingdom Department of Energy, Edition 4, 1990

5) Chen, Y. N. and Thayamballi, A. K., "Calibration of Global Climatology and Loading Characteristics in Fatigue Damage Assessment of Ship Structures", Paper presented to SNAME Marine Structural Inspection, Maintenance and Monitoring Symposium, Arlington, Virginia, March 1991

6) "Global Wave Statistics", Book published by British Maritime Technology (BMT), 1986

7) "Guidance on Some Methods for the Derivation of Acceptance Levels for Defects in Fusion Welded Joints" Document PD6493, British Standards Institution

8) Sumpter, J. D. G., "Practure Toughness of Ship Steels", Paper read at Spring Meeting of the Royal Institution of Naval Architects, 1988 